\title{
PENGGUNAAN METODE SIMULASI TERHADAP KETERAMPILAN WANITA PASANGAN USIA SUBUR (PUS) TENTANG DETEKSI DINI KANKER PAYUDARA DI DESA TEMBUNG KECAMATAN PERCUT SEI TUAN DELI SERDANG TAHUN 2018
}

\author{
Masriati Panjaitan, Idaria Sidabukke, Surya Anita \\ Kebidanan, Universitas Sari Mutiara, surya.anita79@yahoo.co.id
}

\section{INFO ARTIKEL}

RiwayatArtikel:

Diterima: 10-05-2018

Disetujui: 08-06-2018

\section{Kata Kunci:}

Metode Simulasi, keterampilan SADARI

Simulation Method

SADARI Skills

\begin{abstract}
ABSTRAK
Abstrak: Prevalensi kanker payudara tertinggi di Indonesia terdapat di DI.Yogyakarta yaitu sebesar 2,4\% disusul oleh Propinsi Kalimantan Timur sebesar 1,0\% dan Sumatera Barat sebesar $0,9 \%$. Sedangkan di propinsi Sumatera Utara sebesar 0,4\%. SADARI merupakan salah cara deteksi dini untuk mencegah terjadinya kanker payudara akan lebih efektif jika dilakukan sedini mungkin ketika wanita mencapai usia reproduksi. Hasil penelitian Berdasarkan hasil uji $T$ tes diperoleh nilai $p$ value 0,020 yang artinya ada hubungan antara penggunaan metode simulasi dengan peningkatan keterampilan wanita PUS dalam hal deteksi dini kanker payudara dengan metode SADARI.
\end{abstract}

\begin{abstract}
The highest breast cancer prevalence in Indonesia is at Special Region of Yogyakarta, which is 2,4\% then followed by East Kalimantan Province 1,0\%, West Sumatra $0,9 \%$, while in North Sumatrathe percentage is $0,4 \%$. SADARI is one of early detection methods to prevent breast cancer and it will be more effective if it is done as early as possible when women reach the reproduction age. The $T$ test results based on the obtained $p$ value 0,020 revealed that there is a correlation between simulation method usages with PUS women skills improvement in the term of breast cancer early detection by utilizing SADARI method.
\end{abstract}

\section{A. LATAR BELAKANG}

Kanker payudara adalah tumor ganas pada payudara yang berupa benjolan atau massa tunggal yang sering terdapat di daerah kuadran atas bagian luar, benjolan ini keras dan bentuknya tidak beraturan dan dapat digerakkan, kanker payudara ini juga merupakan salah satu jenis kanker yang menjadi penyebab kematian terbesar kaum wanita di dunia (olfah, Mendri dan Badi'ah 2013).

Ancaman kanker di Dunia semakin meningkat seiring dengan perubahan pola hidup masyarakat. Menurut Badan Kesehatan Dunia (WHO) di perkirakan terjadi peningkatan kejadian kanker di dunia 300 persen pada tahun 2030, dan mayoritas terjadi di negara berkembang termasuk Indonesia (Kemenkes RI, 2016).

Berdasarkan data Global of Cancer (GLOBOCAN), International Agency for Research on Cancer (IARC), diketahui bahwa kanker payudara adalah kanker paling umum kedua di dunia dan merupakan kanker yang paling sering diantara perempuan dengan perkiraan 1,67 juta kasus kanker baru yang di diagnosis pada tahun 2012 (25\% dari semua kanker). Tingkat Incidence Rate (IR) bervariasi hampir empat kali lipat di seluruh wilayah dunia, mulai dari 27 kasus per 100.000 di Afrika Tengah dan Asia Timur sampai 92 kasus per 100.000 di Amerika Utara.

Kanker payudara juga menjadi penyebab kedua kematian akibat kanker di daerah yang lebih maju sekitar 198.000 kematian $(15,4 \%)$ setelah kanker paru. Kisaran angka kematian antar wilayah dunia kurang dari itu karena kelangsungan hidup yang lebih menguntungkan dari kanker payudara pada daerah berkembang, mulai dari 6 kematian per 100.000 penduduk di Asia Timur sampai 20 kematian per 100.000 penduduk di Afrika Barat sedangkan angka kematian di Indonesia untuk kanker payudara adalah 16,6 kematian per 100.000 penduduk (Kemenkes RI, 2016).

Penyakit kanker payudara merupakan penyakit kanker dengan prevalensi tertinggi di Indonesia pada tahun 2013 setelah kanker serviks, prevalensi kanker payudara sebesar 0,5\%. Prevalensi kanker payudara tertinggi di Indonesia terdapat di DI. Yogyakarta yaitu sebesar 2,4\% disusul oleh Propinsi Kalimantan Timur sebesar $1,0 \%$ dan Sumatera Barat sebesar 0,9\%. Sedangkan di propinsi Sumatera Utara sebesar $0,4 \%$. Berdasarkan data pasien di RS Kanker Dharmais Jakarta 
selama tahun 2010-2015 kanker payudara merupakan salah satu dari tiga penyakit kanker terbanyak dan jumlah kasus baru serta jumlah kematian akibat kanker terus meningkat. Dari 10 jenis kanker terbanyak, kanker payudara menduduki urutan pertama dalam 10 tahun terakhir sampai dengan tahun 2016 bahkan terjadi peningkatan jumlah kasus setiap tahunnya, proporsi kanker payudara sekitar 40\% dari seluruh kasus kanker di Rumah Sakit tersebut. Besaran masalah kanker payudara di Indonesia dapat dilihat dari pasien kanker payudara yang datang untuk pengobatan, dimana $60-70 \%$ penderita sudah dalam stadium lanjut (Kementerian Kesehatan RI, 2016)

Data Dinas Kesehatan kota Medan menunjukkan bahwa data rekapitulasi kasus kanker tertinggi dari Puskesmas sekota Medan sepanjang tahun 2015-2016 sebanyak 449 kasus kanker payudara. Berdasarkan data Rumah Sakit Umum Daerah (RSUD) dr.Pirngadi Medan, sejak Januari hingga Februari 2015, lebih dari 45 orang pasien yang dirawat di rumah sakit pemerintah ini dikarenakan kanker payudara. Berdasarkan data Rumah Sakit Umum Pusat (RSUP) H.Adam Malik Medan jumlah wanita yang menderita kanker payudara sepanjang tahun 2014 - 2016 ada 1.672 pasien kanker payudara mendapatkan perawatan inap. Sedangkan untuk rawat jalan sekitar 8.993, sehingga totalnya 10.565 yang menderita kanker payudara ( Kepmenkes, 2016).

Beberapa faktor pemicu munculnya kanker payudara pada hidup sehari-hari menjadi momok munculnya kanker payudara. Saat ini tidak ada pengetahuan yang cukup tentang penyebab kanker payudara, karena itu kesadaran deteksi dini merupakan salah satu cara pengendalian kanker payudara. Ketika kanker payudara terdeteksi dini dan diagnosis serta pengobatan yang memadai tersedia, maka akan ada kesempatan bahwa kanker payudara dapat disembuhkan (Kemenkes RI, 2016).

\section{B. METODE PENELITIAN}

\section{a. Jenis Penelitian}

Jenis penelitian yang digunakan dalam penelitian ini eksperimen dengan jenis quasi eksperimen (eksperimen semu) dengan rancangan Non Equivalent Control Group, bertujuan untuk mengetahui efektifitas penyuluhan metode simulasi terhadap keterampilan dalam mencegah kanker payudara secara dini pada wanita PUS.

\section{b. Lokasi dan Waktu Penelitian}

Penelitian dilaksanakan di desa Tembung Kecamatan Percu Sei Tuan kabupaten Deli Serdang Penelitian dimulai pada bulan April - Mei 2018.

\section{c. Sampel}

Wanita PUS di desa Tembung kecamatan Percut Sei Tuan, yaitu 41 orang.

\section{d. Metode Pengumpulan Data}

Metode pengumpulan data pada penelitian ini dengan menggunakan data primer yang diberikan pertanyaan pada saat pre dan post simulasi.

\section{HASIL DAN PEMBAHASAN}

1. Hasil

a. Distribusi Frekuensi Jumlah Nilai Responden Saat Menjawab Soal Pretest Wanita PUS desa Tembung Kecamatan Percut Sei Tuan kabupaten Deli Serdang tahun 2018

\section{Diagram 1}

Distribusi Frekuensi Jumlah Nilai Responden Saat Menjawab Soal Pretest Wanita PUS desa Tembung Kecamatan Percu Sei Tuan kabupaten Deli Serdang tahun 2018

\section{Nilai pretest sebelum simulasi}

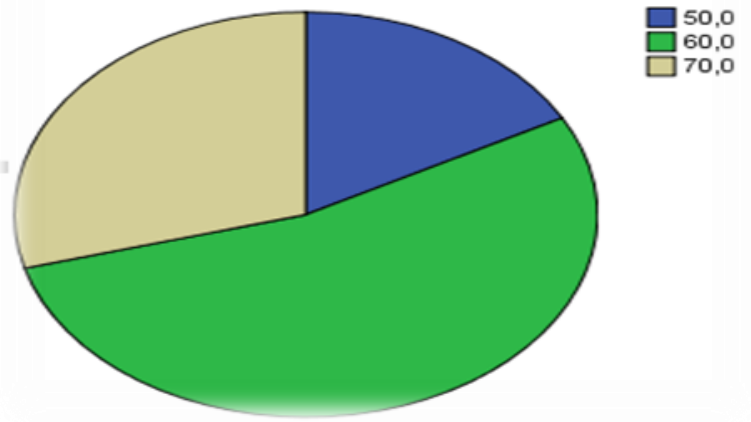

Dari diagram diatas menunjukkan bahwa responden yang menjawab soal pretest mayoritas mendapatkan nilai 60,0 sebanyak 22 orang $(53,7 \%)$

b. Distribusi Frekuensi Jumlah Nilai Responden Saat Menjawab Soal Pretest Wanita PUS desa Tembung Kecamatan Percut Sei Tuan kabupaten Deli Serdang tahun 2018

\section{Diagram 2}

Distribusi Frekuensi Jumlah Nilai Responden Saat Menjawab Soal Posttest Wanita PUS desa Tembung Kecamatan Percu Sei Tuan kabupaten Deli Serdang tahun 2018

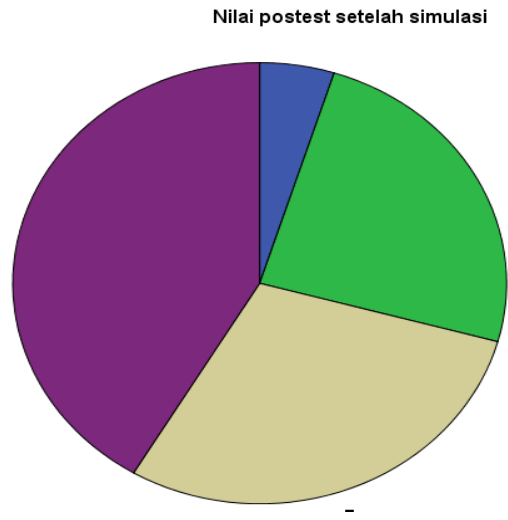


Dari diagram diatas menunjukkan bahwa responden yang menjawab soal postest mayoritas mendapatkan nilai 100,0 sebanyak 17 orang (41,5\%).

\section{c. Hubungan Metode Simulasi dengan Peningkatan Keterampilan SADARI Wanita PUS Desa Tembung Kecamatan Percut Sei Tuan Kabupaten Deli Serdang tahun 2018}

Tabel 1

Distribusi Hubungan Metode Simulasi dengan Peningkatan Keterampilan SADARI Wanita PUS di Desa Tembung Kecamatan Tuan Kabupaten Deli Serdang tahun 2018

\begin{tabular}{|c|c|c|c|c|}
\hline Nilai & Mean & & & $\mathbf{P}$ \\
\hline $\begin{array}{l}\text { Nilai } \\
\text { Pretes }\end{array}$ & 61,21 & 59,079 & 63,360 & 0,020 \\
\hline $\begin{array}{l}\text { Nilai } \\
\text { Postes }\end{array}$ & 90,73 & 87,7884 & 93,6750 & \\
\hline
\end{tabular}

Dari tabel diatas menunjukkan bahwa ada perbedaan nilai rata responden sebelum dan sesudah dimana ratarata nilai pretes 61,21 dan setelah simulasi nilai rata-rata menjadi 90,73 terbukti ada hubungan peningkatan keterampilan setelah dilakukan simulasi dengan nilai $P$ value $(p=0,020)$

\section{Pembahasan}

Berdasarkan hasil uji $T$ tes diperoleh nilai $\mathrm{p}$ value 0,020 yang artinya ada hubungan antara penggunaan metode simulasi dengan peningkatan keterampilan wanita PUS dalam hal deteksi dini kanker payudara dengan metode SADARI.

Metode simulasi sangat efektif untuk meningkatkan keterampilan dalam melakukan SADARI dikarenakan sebagai metode mengajar, simulasi dapat diartikan cara penyajian pengalaman belajar dengan menggunakan situasi tiruan untuk memahami konsep, prinsip, atau keterampilan tertentu.

SADARI adalah pemeriksaan payudara sendiri yang bertujuan untuk mengetahui ada tidaknya kanker dalam payudara wanita. Pemeriksaan ini dilakukan dengan menggunakan cermin oleh wanita yang berumur 20 tahun keatas (Olfah, Mendri, dan Badi'ah 2013). Menurut Mulyani, Rinawati (2013) SADARI adalah pemeriksaan payudara sendiri untuk menemukan adanya benjolan abnormal. Pemeriksaan ini dapat dilakukan sendiri tanpa harus pergi ke petugas kesehatan dan tanpa harus mengeluarkan biaya.

Terbukti 95\% wanita yang terdiagnosis pada tahap awal kanker dapat bertahan hidup lebih dari lima tahun setelah terdiagnosis sehingga banyak dokter yang merekomendasikan agar para wanita menjalani SADARI pada saat menstruasi, pada hari ke 7 sampai dengan hari ke 10 setelah hari pertama haid dirumah secara rutin. Metode SADARI optimum dilakukan pada sekitar 7-14 hari setelah awal siklus menstruasi karena pada masa itu resensi cairan minimal dan payudara dalam keadaan lembut, tidak keras, membengkak sehingga jika ada pembengkakan akan lebih mudah ditemukan.

Penyakit kanker payudara merupakan penyakit kanker dengan prevalensi tertinggi di Indonesia pada tahun 2013 setelah kanker serviks, prevalensi kanker payudara sebesar 0,5\%. Prevalensi kanker payudara tertinggi di Indonesia terdapat di DI.Yogyakarta yaitu sebesar 2,4\% disusul oleh Propinsi Kalimantan Timur sebesar $1,0 \%$ dan Sumatera Barat sebesar 0,9\%. Sedangkan di propinsi Sumatera Utara sebesar 0,4\%. Dari 10 jenis kanker terbanyak, kanker payudara menduduki urutan pertama dalam 10 tahun terakhir sampai dengan tahun 2016 bahkan terjadi peningkatan jumlah kasus setiap tahunnya, proporsi kanker payudara sekitar $40 \%$ dari seluruh kasus kanker di Rumah Sakit tersebut. Besaran masalah kanker payudara di Indonesia dapat dilihat dari pasien kanker payudara yang datang untuk pengobatan, dimana $60-70 \%$ penderita sudah dalam stadium lanjut (Kepmenkes, RI 2016)

Beberapa faktor pemicu munculnya kanker payudara pada hidup sehari-hari menjadi momok munculnya kanker payudara. Saat ini tidak ada pengetahuan yang cukup tentang penyebab kanker payudara, karena itu kesadaran deteksi dini merupakan salah satu cara pengendalian kanker payudara. Ketika kanker payudara terdeteksi dini dan diagnosis serta pengobatan yang memadai tersedia, maka akan ada kesempatan bahwa kanker payudara dapat disembuhkan. (Kemenkes RI, 2016)

Kematian oleh kanker payudara lebih sedikit pada perempuan yang melakukan pemeriksaan SADARI dibandingkan yang tidak SADARI. Sensitivitas SADARI untuk mendeteksi kanker payudara hanya 26\%, bila dikombinasikan dengan mamografi maka sensitivitas mendeteksi secara dini menjadi 75\%.

Berdasarkan hasil uji $T$ tes diperoleh nilai $\mathrm{p}$ value 0,020 yang artinya ada hubungan antara penggunaan metode simulasi dengan peningkatan keterampilan wanita PUS dalam hal deteksi dini kanker payudara dengan metode SADARI.

Metode simulasi sangat efektif untuk meningkatkan keterampilan dalam melakukan SADARI dikarenakan sebagai metode mengajar, simulasi dapat diartikan cara penyajian pengalaman belajar dengan menggunakan situasi tiruan untuk memahami konsep, prinsip, atau keterampilan tertentu.

SADARI adalah pemeriksaan payudara sendiri yang bertujuan untuk mengetahui ada tidaknya kanker dalam payudara wanita. Pemeriksaan ini dilakukan dengan menggunakan cermin oleh wanita yang berumur 20 tahun keatas (Olfah, Mendri, dan Badi'ah 2013). Menurut Mulyani, Rinawati (2013) SADARI adalah pemeriksaan payudara sendiri untuk menemukan adanya benjolan abnormal.pemeriksaan ini dapat dilakukan sendiri tanpa harus pergi ke petugas kesehatan dan tanpa harus mengeluarkan biaya. 
Terbukti 95\% wanita yang terdiagnosis pada tahap awal kanker dapat bertahan hidup lebih dari lima tahun setelah terdiagnosis sehingga banyak dokter yang merekomendasikan agar para wanita menjalani SADARI pada saat menstruasi, pada hari ke 7 sampai dengan hari ke 10 setelah hari pertama haid dirumah secara rutin. Metode SADARI optimum dilakukan pada sekitar 7-14 hari setelah awal siklus menstruasi karena pada masa itu resensi cairan minimal dan payudara dalam keadaan lembut, tidak keras, membengkak sehingga jika ada pembengkakan akan lebih mudah ditemukan.

Penyakit kanker payudara merupakan penyakit kanker dengan prevalensi tertinggi di Indonesia pada tahun 2013 setelah kanker serviks, prevalensi kanker payudara sebesar 0,5\%. Prevalensi kanker payudara tertinggi di Indonesia terdapat di DI.Yogyakarta yaitu sebesar 2,4\% disusul oleh Propinsi Kalimantan Timur sebesar $1,0 \%$ dan Sumatera Barat sebesar 0,9\%. Sedangkan di propinsi Sumatera Utara sebesar 0,4\%. Dari 10 jenis kanker terbanyak, kanker payudara menduduki urutan pertama dalam 10 tahun terakhir sampai dengan tahun 2016 bahkan terjadi peningkatan jumlah kasus setiap tahunnya, proporsi kanker payudara sekitar $40 \%$ dari seluruh kasus kanker di Rumah Sakit tersebut. Besaran masalah kanker payudara di Indonesia dapat dilihat dari pasien kanker payudara yang datang untuk pengobatan, dimana $60-70 \%$ penderita sudah dalam stadium lanjut (Kepmenkes, RI 2016)

Beberapa faktor pemicu munculnya kanker payudara pada hidup sehari-hari menjadi momok munculnya kanker payudara. Saat ini tidak ada pengetahuan yang cukup tentang penyebab kanker payudara, karena itu kesadaran deteksi dini merupakan salah satu cara pengendalian kanker payudara. Ketika kanker payudara terdeteksi dini dan diagnosis serta pengobatan yang memadai tersedia, maka akan ada kesempatan bahwa kanker payudara dapat disembuhkan. (Kemenkes RI, 2016)

Kematian oleh kanker payudara lebih sedikit pada perempuan yang melakukan pemeriksaan SADARI dibandingkan yang tidak SADARI. Sensitivitas SADARI untuk mendeteksi kanker payudara hanya 26\%, bila dikombinasikan dengan mamografi maka sensitivitas mendeteksi secara dini menjadi 75\%.

\section{SIMPULAN DAN SARAN}

\section{Simpulan}

Berdasarkan $\begin{array}{lrr}\text { hasil penelitian } & \text { mengenai } \\ \text { metode } & \text { simulasi } & \text { terhadap }\end{array}$ Penggunaan metode simulasi terhadap
keterampilan wanita PUS tentang deteksi dini kanker payudara di desa Tembung kecamatan Percut Sei Tuan kabupaten Deli Serdang tahun 2018 maka dapat diambil kesimpulan bahwa ada hubungan antara penggunaan metode simulasi dengan peningkatan keterampilan wanita PUS dalam hal SADARI nilai Pvalue $(\mathrm{p}=0,020)$ a. Disarankan kepada semua responden untuk lebih aktif mencara informasi tentang penyakit kanker payudara dan cara mendeteksi secara dini sebagai bagian dari skrining.

b. Disarankan pada petugas kesehatan untuk lebih intesif memberikan penyuluhan ke masyarakat tentang kanker payudara dan cara mendeteksi secara dini

\section{UCAPAN TERIMA KASIH}

Tim penulis mengucapkan terima kasih kepada :

1. Kemristekdikti yang sudah mendanai penelitian ini melalui hibah PDP

2. Rektor USM Indonesia yang sudah memberikan dukungan untuk mengikuti hibah-hibah penelitian dan pengabdian masyarakat

3. LPPM USM Indonesia yang memberikan dukungan dan kesempatan untuk melaksanakan penelitian

\section{DAFTAR RUJUKAN}

[1] Ariani, S. (2015). Stop Kanker. Yogyakarta : Istana Media

[2] Budiman \& Riyanto, A (2013). Kapita Selekta Kuesioner. Jakarta : Salemba Medika

[3] Hidayat, A.A. (2014). Metode Penelitian Kebidanan dan teknik Analisis Data. Jakarta : Salemba Medika

[4] Istarani (2012). Kumpulan 40 Metode Pembelajaran. Medan : Media Persada

[5] Kemenkes RI, (2016). Kanker Payudara. Jakarta

[6] Maryam, S. (2015). Promosi Kesehatan. Jakarta : Buku Kedokteran EGC

[7] Mulyani,S.N, \& Rinawati (2013). Kanker Payudara dan PMS pada Kehamilan. Yogyakarta : Nuha Medika.

[8] Notoatmodjo, S. (2012). Promosi Kesehatan dan Perilaku Kesehatan. Jakarta : Rineka Cipta

[9] Pramitasari, R.D, \& Saryono (2014). Perawatan Payudara. Yogyakarta : Nuha Medika.

[10] Saryono \& Anggraeni, M.D. (2013). Metodologi Penelitian Kualitatif dan Kuantitatif dalam Bidang Kesehatan. Yogyakarta : Nuha Medika

[11] Savitri, A. dkk (2015). Kupas Tuntas Kanker Payudara Leher Rahim \& Rahim. Yogyakarta : Pustaka Baru Press

[12] Sumiati \& Asra (2016). Metode Pembelajaran. Bandung : Wacana Prima

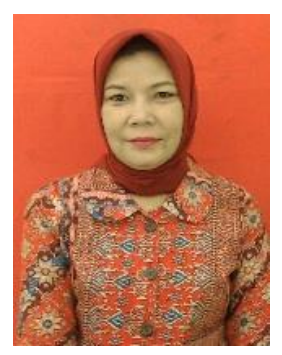

PROFIL PENULIS UTAMA

Nama : Masriati Panjaitan, SST, M.Kes TTL : Tanjung Balai 27 Maret 1969 Riwayat Pendidikan: D4 Keperawatan Maternitas USU, S2 Kesehatan Masyarakat USU

Tempat Bekarja: Universias Sari Mutiara Indonesia

Riwayat Penelitian

2. Saran 
1. Hubungan tingkat pengetahuan ibu tentang Stimulasi verbal dengan tindakan membacakan cerita pada anak di Puskesmas Desa Binjai Medan tahun 2014

2. Analisis Faktor-faktor Yang Mempengaruhi Kunjungan Voluntary Counseling and Testing (VCT) HIV/AIDS Di Kalangan Ibu Rumah Tangga Di Daerah Beresiko Tinggi tahun 2017 